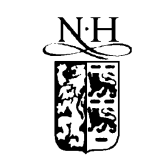

ELSEVIER
Journal of International Money and Finance

20 (2001) 591-609
Journal of

International

Money

and Finance

\title{
Emerging market debt: measuring credit quality and examining relative pricing
}

\author{
Robert E. Cumby ${ }^{a, *}$, Tuvana Pastine ${ }^{b}$ \\ a School of Foreign Service, Georgetown University, Washington, DC 20057, USA \\ ${ }^{\mathrm{b}}$ Department of Economics, Bilkent University, Ankara, Turkey
}

\begin{abstract}
We investigate the pricing of 'Brady' bonds that are issued by the governments of five developing countries as part of debt and debt service reduction agreements. We first present a measure of credit quality that takes account of the individual features of each bond and is comparable across bonds, across issuers, and over time. We then examine the evolution of the credit quality of each debt instrument from 1990 until the beginning of 2000. Next, we present evidence of a profitable trading strategy that exploits the information contained in this measure of credit quality. (c) 2001 Elsevier Science Ltd. All rights reserved.
\end{abstract}

JEL classification: F32; F34

Keywords: Emerging market debt; Credit risk; Brady bonds

\section{Introduction}

Since 1990 the secondary market for developing country debt has become more liquid due to the introduction of 'Brady' bonds, which were issued as part of debt and debt service reduction agreements. Brady bonds account for $>30 \%$ of total trading volume in emerging market debt. The importance of the market and high secondary market turnover ${ }^{1}$ makes the prices of Brady bonds one of the potentially most useful sources of information about developing country credit risk. ${ }^{2}$

\footnotetext{
* Corresponding author. Tel.: +1-202-687-5696; fax: +1-202-687-6102.

E-mail address: cumbyr@georgetown.edu (R.E. Cumby).

${ }^{1}$ Brady bonds had over US\$178 billion in trading volume in just the third quarter of 1999.

${ }^{2}$ In 1999 Ecuador became the first country to default on its Brady bond payments. Ecuador defaulted on its entire stock of US\$6 billion in Brady debt.
} 
Under the Brady initiative, creditors were presented with a menu of alternatives to restructure the outstanding debt. A borrower therefore frequently has several Brady issues, each with different features. For example, some include enhancements such as principal guarantees and limited interest guarantees. The bonds also differ in their maturities and their coupon payments - some have fixed rates, some have floating rates, and some convert from fixed to floating rates after several years.

We examine a sample consisting of 14 Brady bonds issued by the governments of Argentina, Brazil, Mexico, the Philippines, and Venezuela from 1990 until the beginning of 2000 and pursue two aims. The first is to present a summary measure of credit quality that is comparable across bonds with different features, across issuers, and across time. The second is to examine evidence of mispricing in the Brady bond market.

Yields to maturity or prices of debt instruments issued by developing countries are often cited as barometers of credit risk. Numerous studies use secondary market prices of sovereign debt to examine the determinants of credit quality. ${ }^{3}$ This literature asks important questions - an understanding of the determinants of the perceived credit quality is critical for both the borrower and the lender and the assessment of the credit quality is obviously important for pricing new debt and for formulating debt restructuring agreements. Although bond price or yield movements can be used as a quick reference for the perceived repayment capacity of the borrower, they are imperfect measures of credit risk. The prices and the yields of bonds with different characteristics will differ at any point in time and they will react differently to changes in economic conditions. This problem is especially severe for Brady bonds because non-negligible default risk has led to innovative features in these bonds. For example, the price and yield of a bond with guaranteed principal will be less sensitive to changes in credit quality than the price and yield of a bond without a guarantee. Similarly, different coupons, maturities, and amortization schedules will lead to different elasticities of prices with respect to interest rates and/or perceived credit quality.

The summary measure of credit risk we present is the default probability implied by observed market prices. These implied default probabilities provide a potentially useful indicator that takes into account all of the features of each individual bond. They have the advantage of being comparable across borrowers and across debt instruments with different characteristics and should change over time only in response to changes in perceived credit risk. Consistent with this, we find that differences in the implied default probabilities across bonds issued by a given borrower are much smaller than the corresponding differences in prices. Hence, they may prove to be useful in studies of the underlying factors that explain perceived credit quality. They also turn out to be a useful input into our examination of pricing in the market.

${ }^{3}$ Examples include Edwards (1986), Sachs and Huizinga (1987), Berg and Sachs (1988), Purcell and Orlanski (1988), Hajivassiliou (1989), Boehmer and Megginson (1990), Stone (1991), Fernandez and Ozler (1991) and Ozler and Huizinga (1992). 
The paper is structured as follows. We describe the debt instruments included in this study in Section 2. Next, in Section 3, we compute a summary measure of credit quality, the implied default probability, for each bond and examine the evolution of these probabilities over time. In Section 4, we examine the information contained in the implied default probabilities. Although the implied default probabilities should reflect only the credit risk of the borrower, we find differences in these probabilities across bonds issued by the same borrower. If the cause of the differences is pricing errors, underpriced bonds should have high implied default probabilities and overpriced bonds should have low implied default probabilities. We find that trading strategies using differences in the implied default probabilities to identify overvalued and undervalued bonds are indeed profitable. The success of these trading strategies thus appears to reflect anomalies in the relative pricing of a given borrower's issues.

\section{Description of the debt instruments}

The sample begins in 1990, when the first Brady bonds were issued by the government of Mexico, and goes through the beginning of $2000 .{ }^{4}$ The data consist of weekly (Wednesday) price quotes that we obtained from a large investment bank active in the market. ${ }^{5}$ For all 14 bonds issued by the governments of Argentina, Brazil, Mexico, the Philippines and Venezuela, we use the longest sample of price quotes available.

Table 1 describes the general terms and features of the bonds in our sample. ${ }^{6}$ The Mexican Brady deal, which was the first, presented creditors with the choice of making new loans, converting bank debt at par for a fixed-rate bond with a belowmarket coupon, or converting bank debt at a discount for floating rate bonds with a spread of 13/16 over LIBOR. ${ }^{7}$ An innovative feature of Mexico's Brady deal is the use of collateral. The principal is collateralized by zero-coupon US Treasury bonds that were purchased by the Mexican government. In addition, high-quality shortterm securities were placed in an escrow account to guarantee 18 months of interest. If the interest guarantee remains unused (as it has thus far), the securities in the escrow account roll over to provide an ongoing interest guarantee.

Subsequent Brady deals built on the menu approach of the Mexican deal, generally expanding the number of options in the menu but retaining the use of collateral for some of the options. ${ }^{8}$ Among the features found in later Brady deals are front-loaded

\footnotetext{
${ }^{4}$ The Mexican agreement was reached in 1989, but the bonds were issued in 1990 .

5 When Wednesday prices are not available (primarily due to holidays), the closest available price is used.

6 As reported in Table 1, the sample for Brazil is the shortest - the Brazilian Brady deal took place in 1994. The Philippines' Brady agreement took place in two stages so the two bonds have different samples.

${ }^{7}$ Conversion occurred at US\$65 face value of the floating-rate bonds per US\$100 face value of bank debt. Thus 'par' and 'discount' refer to conversion terms, not to features of the bonds.

${ }^{8}$ Every country in our sample issued bonds with collateralized principal and bonds with some collateralized interest payments.
} 
Table 1

General terms and features of the Brady bonds ${ }^{\mathrm{a}}$

\begin{tabular}{|c|c|c|c|}
\hline & \multicolumn{3}{|l|}{ Argentina } \\
\hline & Discount bonds (Discount) & Par bonds (Par) & PDI bonds (PDI) \\
\hline Date of issue & 31 March 1993 & 31 March 1993 & 31 March 1993 \\
\hline Size of issue & US\$4.5 billion & US\$13 billion & US\$8.21 billion \\
\hline Final maturity & March 2023 & March 2023 & March 2010 \\
\hline Coupon rate & LIBOR+13/16\% & $\begin{array}{l}4 \%, \text { rises to } 6 \% \text { in } \\
\text { year seven }\end{array}$ & LIBOR $+13 / 16 \%$ \\
\hline Amortization & Bullet amortization & Bullet amortization & $\begin{array}{l}\text { Graduated amortization } \\
7 \text { year grace period }\end{array}$ \\
\hline Principle & Collateralized by US & Collateralized by US & None \\
\hline Guarantee & Treasury zeros & Treasury zeros & \\
\hline Interest & 12 months of interest & 12 months of interest & None \\
\hline \multirow[t]{3}{*}{ Guarantee } & Guarantee at $8 \%$ & Guarantee at $6 \%$ & \\
\hline & \multicolumn{3}{|l|}{ Brazil } \\
\hline & C-Bonds (C) & $\begin{array}{l}\text { Discount bonds } \\
\text { (Discount) }\end{array}$ & Par bonds (Par) \\
\hline Date of issue & 15 April 1994 & 15 April 1994 & 15 April 1994 \\
\hline Size of issue & US\$7.055 billion & US $\$ 7.3$ billion & US $\$ 10.523$ billion \\
\hline Final maturity & 15 April 2014 & 15 April 2024 & 15 April 2024 \\
\hline Coupon rate & $\begin{array}{l}4 \% \text { rises to } 8 \% \text { in year } \\
\text { seven }\end{array}$ & LIBOR $+13 / 16 \%$ & $\begin{array}{l}4 \% \text { rises to } 6 \% \text { in year } \\
\text { seven }\end{array}$ \\
\hline Amortization & $\begin{array}{l}21 \text { equal installments } \\
\text { starting October } 2004\end{array}$ & Bullet amortization & Bullet amortization \\
\hline Principle & None & Collateralized by US & Collateralized by US \\
\hline Guarantee & & Treasury zeros & Treasury zeros \\
\hline Interest & None & 12 months of interest & 12 months of interest \\
\hline Guarantee & & Guarantee at $8 \%$ & Guarantee at $6 \%$ \\
\hline \multirow[t]{3}{*}{ Special features } & $\begin{array}{l}\text { Difference between } 8 \% \\
\text { and interest rate is } \\
\text { capitalized }\end{array}$ & & \\
\hline & Mexico & & \\
\hline & Par bonds (Par) & $\begin{array}{l}\text { Discount bonds } \\
\text { (Discount) }\end{array}$ & \\
\hline Date of issue & 28 March 1990 & 28 March 1990 & \\
\hline Size of issue & US\$21 billion & US\$12 billion & \\
\hline Final maturity & 31 December 2019 & 31 December 2019 & \\
\hline Coupon rate & $6.25 \%$ pa & LIBOR $+13 / 16 \%$ pa & \\
\hline Amortization & Bullet amortization & Bullet amortization & \\
\hline Principle & Collateralized by US & Collateralized by US & \\
\hline Guarantee & Treasury zeros & Treasury zeros & \\
\hline Interest & 18 months of interest & 18 months of interest & \\
\hline Guarantee & Payments at $6.25 \%$ pa & Payments at $10 \%$ pa & \\
\hline
\end{tabular}


Table 1 (continued)

\begin{tabular}{|c|c|c|c|}
\hline & Philippines & Venezuela & \\
\hline & $\begin{array}{l}\text { Principle collateralized } \\
\text { interest reduction bonds } \\
\text { (PCIR) }\end{array}$ & $\begin{array}{l}\text { New money bonds } \\
\text { (NM) }\end{array}$ & $\begin{array}{l}\text { Front-loaded interest } \\
\text { reduction bonds } \\
\text { (FLIR) }\end{array}$ \\
\hline Date of issue & 9 December 1992 & 15 May 1990 & 18 December 1990 \\
\hline Size of issue & US\$1.889 billion & US\$ 860 million & US\$2.6 billion \\
\hline Final maturity & December 2017 & 5 January 2005 & 31 March 2007 \\
\hline Coupon rate & $\begin{array}{l}4.25 \% \text { rises to } \\
6.5 \% \text { in year six, quarterly } \\
\text { in years } 1 \text { and } 2 \text {, semi- } \\
\text { annually, thereafter }\end{array}$ & LIBOR $+13 / 16 \%$ & $\begin{array}{l}5 \%, 5 \%, 6 \%, 6 \%, 7 \% \text { in } \\
\text { first } 5 \text { years, then } \\
\text { LIBOR }+7 / 8 \%\end{array}$ \\
\hline Amortization & Bullet amortization & $\begin{array}{l}15 \text { equal semi-annual } \\
\text { installments } \\
\text { Starting } 5 \text { January } \\
1998\end{array}$ & $\begin{array}{l}21 \text { semi-annual } \\
\text { installments } \\
\text { Starting } 31 \text { March } \\
1997\end{array}$ \\
\hline Principle & Collateralized by US & None & None \\
\hline Guarantee & Treasury zeros & & \\
\hline Interest & 14 months of interest & None & $\begin{array}{l}12 \text { months of interest, } \\
\text { first } 5 \text { years only }\end{array}$ \\
\hline \multirow[t]{3}{*}{ Guarantee } & Payments at $6.5 \%$ & & \\
\hline & Venezuela & & \\
\hline & Par bonds (Par) & $\begin{array}{l}\text { Discount bonds } \\
\text { (Discount) }\end{array}$ & $\begin{array}{l}\text { Debt conversion bonds } \\
\text { (DC) }\end{array}$ \\
\hline Date of issue & 18 December 1990 & 18 December 1990 & 18 December 1990 \\
\hline Size of issue & US\$6.7 billion & US $\$ 1.18$ billion & US\$5.353 billion \\
\hline Final maturity & 31 March 2020 & 31 March 2020 & 18 December 2007 \\
\hline Coupon rate & Fixed $6.75 \%$ & LIBOR+13/16\% & LIBOR+7/8\% \\
\hline Amortization & Bullet amortization & Bullet amortization & $\begin{array}{l}21 \text { Semi-annual } \\
\text { installments starting } 18 \\
\text { December } 1997\end{array}$ \\
\hline Principle & Collateralized by US & Collateralized by US & None \\
\hline Guarantee & Treasury zeros & Treasury zeros & \\
\hline Interest & 14 month of interest & 14 months of interest & None \\
\hline Guarantee & Guarantee at $6.75 \%$ & Guarantee at $9.75 \%$ & \\
\hline
\end{tabular}

a Note: the abbreviations used to refer to the bonds in subsequent tables are given in parentheses.

interest-reduction bonds, which have a coupon rate that is low initially but rises in steps over time and converts to a floating market rate after several years.

Table 2 presents summary statistics for each bond in our sample. In addition to the mean bond price, it contains the mean and variance of the annualized (uncompounded) weekly rates of return. The average prices differ substantially across a given borrower's bonds reflecting, at least in part, different features of the bonds. We will examine whether differences in the bonds' features explain all of the price differences.

Differences in the features of the bonds are also reflected in differences in the volatilities of the rates of return. For example, adding credit enhancements affects both the volatility of returns and the average price. The price of a bond with principle 
Table 2

Summary statistics: prices and rates of return ${ }^{\mathrm{a}}$

\begin{tabular}{lllll}
\hline & $\begin{array}{l}\text { Number of } \\
\text { observations }\end{array}$ & Mean price & $\begin{array}{l}\text { Mean rate } \\
\text { of return }\end{array}$ & $\begin{array}{l}\text { Variance of } \\
\text { rate of return }\end{array}$ \\
\hline $\begin{array}{l}\text { Argentina } \\
\text { Discount }\end{array}$ & 353 & & & \\
Par & 353 & 72.4 & 0.142 & 2.769 \\
PDI & 353 & 60.3 & 0.161 & 2.628 \\
Brazil & & 79.0 & 0.172 & 3.772 \\
Discount & 298 & & & 2.829 \\
Par & 298 & 68.071 & 0.182 & 2.863 \\
C & 298 & 56.631 & 0.214 & 5.443 \\
Mexico & & 63.076 & 0.246 & 1.231 \\
Discount & 510 & & & 1.412 \\
Par & 510 & 80.274 & 0.133 & 1.525 \\
Philippines & & 66.715 & 0.181 & 0.656 \\
PCIR & 369 & & & \\
NM & 428 & 77.442 & 0.147 & 1.835 \\
Venezuela & & 85.928 & 0.115 & 2.118 \\
Discount & 472 & & & 3.113 \\
Par & 472 & 68.646 & 0.104 & 3.251 \\
FLIR & 472 & 64.021 & 0.163 & \\
DC & 472 & 66.914 & 0.147 & \\
\hline
\end{tabular}

a Note: the last two columns report the mean and the variance of the annualized (uncompounded) weekly rates of return.

and interest guarantees should be less sensitive to changes in the credit quality, yielding a lower volatility in rates of return. This can be seen by comparing the two Venezuelan floating rate bonds [the debt conversion (DC) and discount bonds], the two Brazilian fixed rate bonds (the $\mathrm{C}$ and par bonds), or the two Argentinean floating rate bonds (the PDI and discount bonds).

Fig. 1 plots the prices of the Brady bonds on logarithmic scale. The prices of the Mexican bonds illustrate trends that are found in the issues of several other countries as well. The prices of the Mexican bonds rise on average from 1990 to 1994, possibly reflecting investor perceptions of improved credit quality. The price of the fixed-rate bond (the par bond) rises more rapidly than the price of the floating-rate bond (the discount bond), reflecting falling long-term interest rates over this period. In 1994, both prices fall somewhat, but with rising long-term interest rates, the price of the fixed-rate bond falls by more than the price of the floating-rate bond. Different interest rate elasticities of the prices of the floating and fixed-rate bonds can also be seen in the bonds issued by the government of the Philippines.

The effect of the so-called Tequila crisis in 1995, which was sparked by the Mexican devaluation in December 1994, can be detected in the drop of the prices of the debt instruments of all five borrowers. The second major drop in the prices came in August 1998, which was triggered by the Russian announcement of devaluation and default on its ruble debt. The effect of the announcement is observable in the bond 

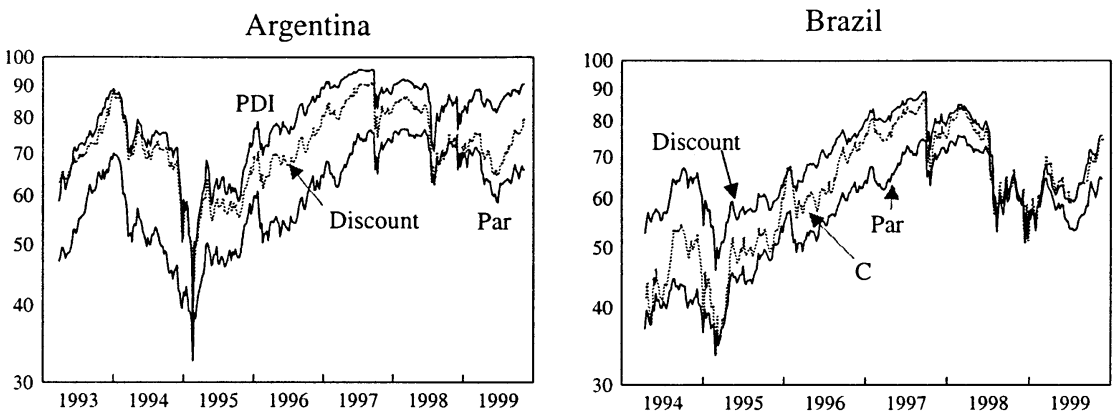

Mexico

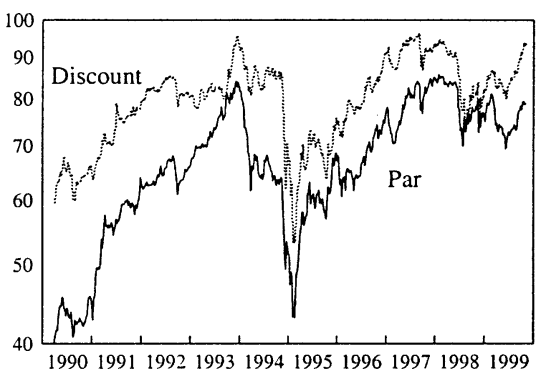

Philippines

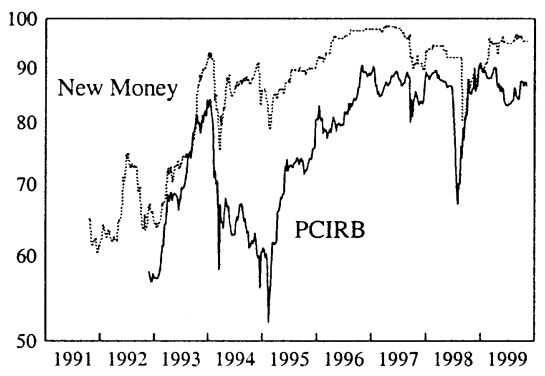

Venezuela
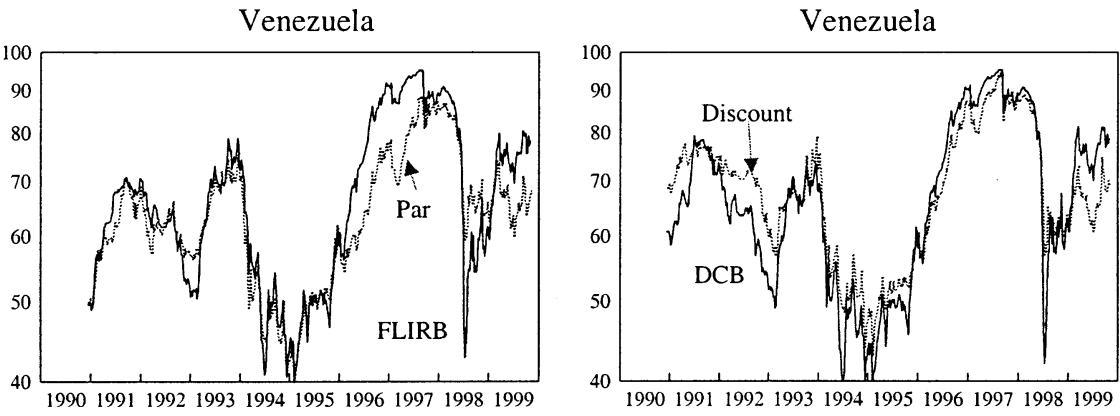

Fig. 1. Brady bond prices.

prices of all our borrowers. Venezuela has been among the hardest hit. The prices of the Venezuelan bonds dropped by about $13 \%$ within a week after the Russian default.

The impact of credit enhancements seen in Table 2 is also reflected in the prices. Bonds with principal and/or interest guarantees tend to exhibit less sensitivity to changes in credit quality. For example, the Venezuelan DC and discount bonds both pay a floating coupon rate. Because the DC bond has no enhancements, its price should exhibit greater sensitivity to changes in credit quality and a greater price variability of the DC bond is observable in the price plots. 


\section{A summary measure of credit quality}

In this section we present a summary measure of credit quality that takes account of the terms of each bond and is comparable across bonds, across issuers, and over time. Much of the work on the pricing of risky debt (generally taken to be corporate debt) follows Merton (1974) and assumes the value of a firm's assets follows an exogenously-specified stochastic process. ${ }^{9}$ But empirical implementation of these models is difficult because the value of the firm's assets can be hard to measure. And its counterpart, the willingness of the government to service the debt is unobservable for sovereign debt. ${ }^{10}$ We therefore adopt a straightforward, albeit somewhat more restrictive approach to valuing risky debt that has been used by Bierman and Haas (1975), Yawitz (1977) and Yawitz et al. (1985) in studies of the pricing of corporate debt. The basic idea is to use the equality between the price of a bond and the present value of the expected future cash flows from the bond to compute the implied default probability each period. We then use this implied default probability as our measure of credit quality. As new information arrives, market participants update their perception of credit quality, which then is reflected in the price of the bond. Hence we are able to compute a time series of this simple measure of credit quality.

Let $\rho_{t}(s)$ be the probability at time $t$ that the bond is therefore in default at $t+s$, conditional on no default occurring prior to $t+s$. At each point in time, the conditional probability is assumed to be constant at each horizon, $s$. That is $\rho_{t}(s) \equiv \rho_{t} \forall s .{ }^{11}$ The conditional probability is updated, each period.

We now describe how to compute $\rho_{t}$. First consider the coupon payments on a fixed-rate bond with $\mathrm{N}$ periods to maturity that is not in default at $t{ }^{12}$ For a riskless bond, the time- $t$ value of a coupon due at $t+s$ would be $r F /\left(1+r_{t, s}\right)^{s}=r F p_{t}(s)$, where $F$ is the face value of the bond, $r$ is the bond's coupon rate, and $r_{t, s}$ and $p_{t}(s)$ are the yield and price at $t$ of a US Treasury zero-coupon bond maturing at $t+s$. Since there is a non-zero probability of default, we multiply the present value of the payment at $t+s$ by $\left(1-\rho_{t}\right)^{s}$, the probability that no default occurs between $t$ and $t+s$.

If a pool of collateral is used to guarantee some of the bond's coupon payments, and the bond goes into default at $t+s$, the coupon payments at $t+s, t+s+1$, and so on will be met by drawing on the pool of collateral until the pool is exhausted. Once the pool has been depleted, no further coupon payments will be made. Suppose the pool covers $q$ payments. ${ }^{13}$ The value at $t$ of a pool first used at $t+s$ is

\footnotetext{
${ }^{9}$ Work by Kim et al. (1993), Longstaff and Schwartz (1995) and Leland and Toft (1996) extends Merton's approach in a number of directions.

${ }^{10}$ Claessens and Pennachhi (1996) have had some success in estimating a model with unobserved credit quality by using a linearized Kalman filter. Another alternative, pursued by Jarrow et al. (1994) and Das and Tufano (1995) uses credit ratings as a measure of default risk.

11 The unconditional probability (as of $t$ ) of default at $t+s$ is $1-\left(1-\rho_{t}\right)^{s}$, which rises with $s$.

12 The maturity, $N$, and other features will differ across bonds but, to keep notation as simple as possible, we do not introduce an index for the bond.

${ }^{13}$ If the collateral does not cover an integer number of coupons, the last one will be partial.
} 
$r F\left[p_{t}(s)+p_{t}(s+1)+\ldots+p_{t}(s+q)\right]$. To obtain the expected present value at $t$ of the pool, this needs to be multiplied by $\rho_{t}\left(1-\rho_{t}\right)^{s-1}$, the probability that default first occurs at $s$.

The present value of the principal of a riskless bond or a bond with collateralized principal is $p_{t}(N) F \cdot{ }^{14}$ If the principal is not collateralized, the expected present value is calculated by multiplying this by the probability of no default over the remaining life of the bond, $\left(1-\rho_{t}\right)^{N}$.

The price of the bond, $P_{t}$, should be equal to the sum of the expected present values of the individual components. A bond with $N$ periods to maturity, a coupon rate of $r$, a rolling interest guarantee for $q$ coupons, and collateralized principal should sell for:

$$
P_{t}=r F \sum_{i=1}^{N}\left(p_{t}(i)(1-\rho)^{i}+(1-\rho)^{i-1} \rho \sum_{j=1}^{\min [\mathbf{q}, \mathbf{N}-\mathbf{i}]} p_{t}(j)\right)+p_{t}(N) F
$$

For each bond, we adapt (1) to take account of the bond's features and solve for the value of $\rho_{t}$ that equates the market price with the value of the bond, at each period of time. ${ }^{15}$

We value a floating-rate bond in a similar way. The only difference arises from the adjustment of the interest rate each period. Let $r_{t}(i) F$ be the coupon paid at time $t+i$ on a floating rate bond with face value $F$. The coupon rate is $r_{t}(i)=r L_{t}(i)+s p d$, where $r L_{t}(i)$ is the one-period LIBOR rate determined at $t+i-1$ for payment at $t+i$ and spd is the spread over LIBOR that is paid on the bond. Of course future LIBOR is unknown and cannot be used to value the bond. Instead we use the implied oneperiod forward interest rate computed from the term structure of zero coupon rates. ${ }^{16}$ The implied one-period US Treasury rate to be paid at $t+k$ is given by $p_{t}(k-$ $1) / p_{t}(k)-1$. US Treasury rates are lower than LIBOR, so the spread of LIBOR is added over one-period Treasury rates to obtain the implied forward one-period LIBOR. Eq. (1) then becomes

$$
P_{t}=F \sum_{i=1}^{N}\left(r_{t}(i) p_{t}(i)(1-\rho)^{i}+(1-\rho)^{i-1} \rho \sum_{j=1}^{\min (\mathbf{q}, \mathbf{N}-\mathbf{i})} r_{t}(i+j) p_{t}(i+j)\right)+p_{t}(N) F
$$

\footnotetext{
${ }^{14}$ If the bond is amortized over time, the calculation of the expected present value of the principal is adjusted accordingly.

15 Prices of US Treasury zero-coupon bonds are obtained from the yield curve of coupon-paying securities with three and six months and one, two, five, seven, 10, and 30 years to maturity. Cubic splines are then used to compute yields to maturity for each maturity from 1 week to 30 years. These yields are in turn used recursively to compute the implied yields on zero-coupon securities.

${ }^{16}$ Using the implied forward rates does not require that we adopt the expectations theory of the term structure as the following investment strategy makes clear. Consider a floating rate bond that pays $r_{t+1}$ in period $t+2$. The period $t$ market value of this payment can be obtained by considering the following strategy. Let $f$ be the period $t$ forward price of a one period bond issued in $t+1$. (a) Buy $(1-f) /\left(1+r_{t}\right)$ units of a one period bond at $t$; (b) sell one forward contract; (c) with the proceeds from the first two parts, buy $r_{t+1} /\left(1+r_{t+1}\right)$ units of a one period bond issued at $t+1$. The cash flows are $(1-f) /\left(1+r_{t}\right)$ in period $t$, zero in period $t+1$, and $r_{t+1}$ in period $t+1$. The market value of $r_{t+1}$ paid in $t+2$ must then be $(1-$ $f) /\left(1+r_{t}\right)$. Since $f=1 /\left(1+r f_{t+1}\right)$, this market value is $r f_{t+1} /\left(1+r_{t}\right)\left(1+r f_{t+1}\right)=r f_{t+1} p_{t}(2)$, which is the present value of $r f_{t+1}$.
} 
The implied value of $\rho_{t}$ can be obtained by solving (2) for the value that equates the market price with the present value of the expected payments.

These estimates should be interpreted as summary measures of credit quality rather than as true (actuarial) probabilities for at least two reasons. First, interpreting them as true default probabilities would require that we assume agents are risk neutral, default risk is diversifiable, or we interpret the probabilities as risk-neutral probabilities. But as $\mathrm{Wu}$ and $\mathrm{Yu}$ (1996) show in their examination of the credit risk of corporate bonds, failing to account for risk aversion may result in overestimates of implied default rates. Second, our estimates overstate true default probabilities because we assume that recovery rates are zero.

Fig. 2 contains plots of the annualized implied default probabilities for the bonds
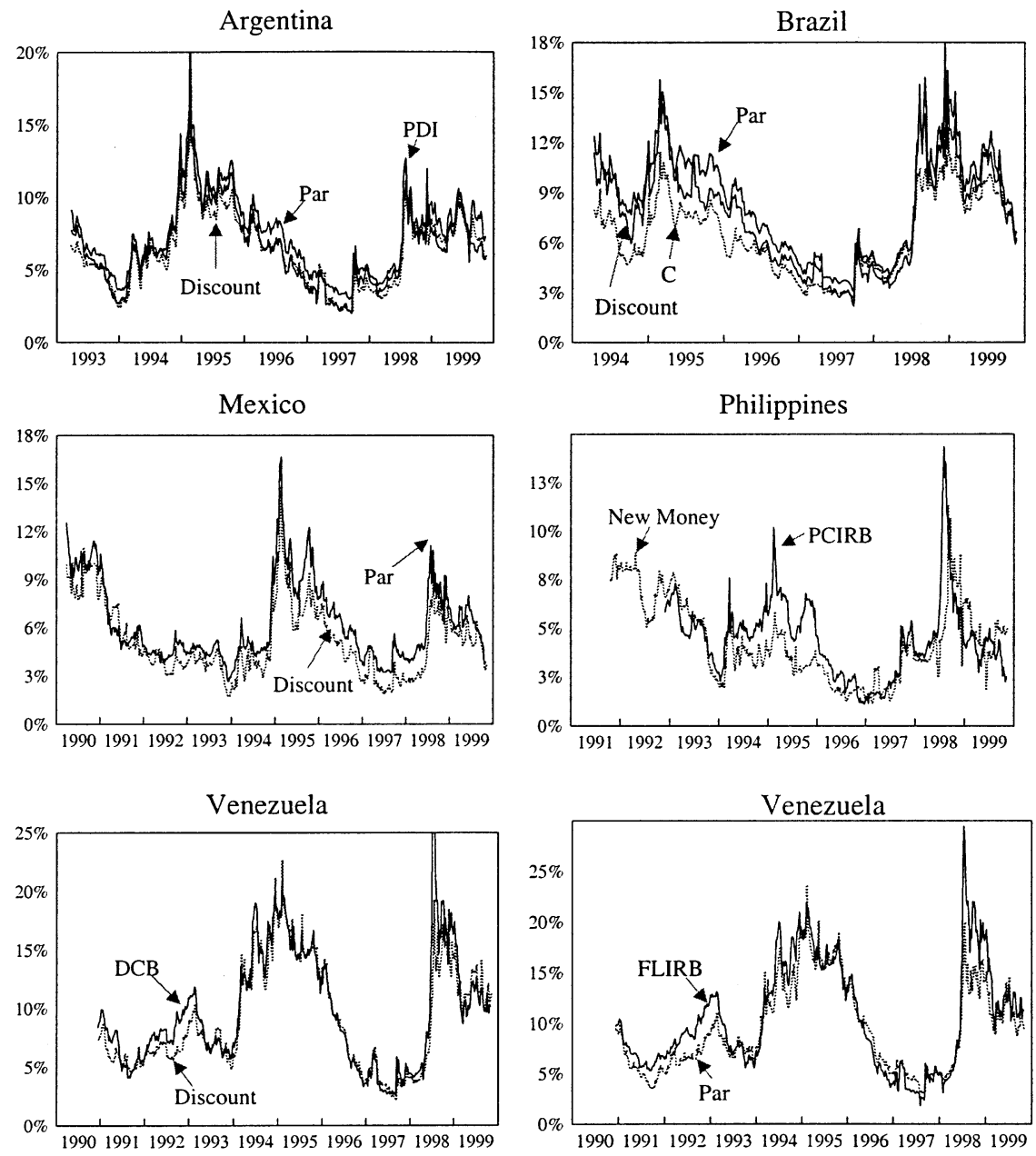

Fig. 2. Implied default probabilities. 
issued by the governments of Argentina, Brazil, Mexico, the Philippines and Venezuela. These estimates illustrate the advantage of using our measure rather than price as an indicator of credit quality. Although the prices of each borrower's issues differ considerably from each other reflecting the individual features of each bond, the corresponding estimates of the implied default probabilities follow each other closely.

Again, we focus on the Mexican bonds to illustrate broader trends. As it was suggested by the bond prices, market perceptions of credit quality improved sharply in 1991 and continued to improve somewhat in 1992. The implied default probabilities then fluctuate during 1993 (a late 1993 NAFTA effect is noticeable). The probabilities increase drastically at the end of 1994 and beginning of 1995 due to the Mexican crisis. The implied default probabilities of the debt instruments of other countries exhibit similar trends. Fig. 2 also demonstrates that the 1998 Russian crisis lead to a drastic sudden deterioration of perceived credit quality for all borrowers.

As we argue above, the implied default probabilities are useful not just for the questions we will address. They are also potentially valuable as a substitute for the raw price or yield of debt instruments in the literature that seeks to explain the secondary-market price (or discount) on the debt of developing countries. Comparing the yields of two bonds issued by different borrowers may not be informative about the relative credit quality of the two borrowers if the bonds have different features. The bond with guarantees will tend to have a lower yield, compared to the bond without enhancements. For instance, in a cross country study where the researcher might be examining the relation between the openness of the countries and the perceived credit quality, the comparability of the measure used for the credit quality across borrowers will be vital. The measure of credit quality we compute may be attractive because it that takes the heterogeneity of the instruments into account.

When the features of the bonds are not constant over time, our implied default probabilities may be an improvement over the yield and/or price as a measure of credit quality, in time series studies. For instance, the Venezuelan FLIR bond has a 12-month interest guarantee for the first 5 years only. At the beginning of the 5 years, the yield of this bond will be less sensitive to changes in the default risk than toward the end of the 5 years where the yield of the bond will become more and more sensitive to changes in the default risk. Hence, the yield of this bond would be expected to be lowest at the beginning of its life time, even if the default risk and all other macroeconomic variables were to stay constant. Our measure of credit quality should change over time only in response to perceived credit risk.

\section{Is there evidence of mispricing?}

Tests of mispricing or market efficiency often examine the predictability of excess returns. But predictable excess returns may signal risk premia that vary over time rather than mispricing. The expected holding period return on a risky bond can be thought of as the sum of the expected holding period return on a riskless bond and a premium for default risk. The premium for default risk is likely to be autocorre- 
lated. In fact, the implied default probabilities reported in Section 3 exhibit substantial autocorrelation. Thus any observed autocorrelation in the excess returns on risky bonds may be capturing the autocorrelation in the default risk premium rather than mispricing. Tests for predictability that regress excess holding-period returns on information other than just lagged returns, such as the yield spread are also problematic in these markets. Default risk is likely to be correlated with yield spreads so that a significant coefficient on the yield spread may capture default risk rather than mispricing. For these reasons, we pursue alternative tests to examine pricing in the Brady bond market.

\subsection{Implied default probabilities}

Although the implied default probabilities estimated for a given borrower are much closer than the corresponding prices, differences do arise. For example, the implied default probability of the Brazilian par bond generally exceeds that of the Brazilian $\mathrm{C}$ bond, and the implied default probability of the Mexican par bond generally exceeds that of the Mexican discount bond, frequently by sizable amounts. ${ }^{17}$ But because the features of each issue are taken into account when the implied default probabilities are computed, the probabilities should reflect pure credit risk, which should be identical for all issues of a given borrower. ${ }^{18}$

Are the differences in the implied default probabilities economically meaningful? We can express the differences in dollar terms by using the implied default probabilities to compute the price of a 'standardized bond,' for example a 10-year zero coupon bond. The difference in the average implied default probabilities for the two Mexican bonds corresponds to a price difference of US\$5.80, or $11.1 \%$ of the standardized price computed from the par bond's average implied default probability.

Why might we find differences in the implied default probabilities? One possibility is that we incorrectly assume that the conditional default probability is constant. Suppose, for instance, lenders are more pessimistic about the distant future than about the near future. In other words, conditional default probabilities, $\rho_{t}(s)$, might be rising with the horizon, $s$, so that term structure of credit risk has positive slope. If conditional default probabilities do in fact rise with the horizon and we assume them to be constant, we would compute lower implied default probabilities for bonds with shorter times to maturity. Likewise, if lenders are more optimistic about the distant future, this would imply a downward-sloping term structure of credit risk. And our constant conditional default probability specification would give us higher implied default probabilities for bonds with shorter times to maturity, even though bonds issued by the same borrower are facing the identical credit risk.

\footnotetext{
${ }^{17}$ In the first quarter of 1998 , the gap reached 1.4 percentage points at a time when the implied default probability of the Mexican discount bond was just $2.6 \%$.

18 In late August 1999, the government of Ecuador suggested skipping payment on their discount bonds but continuing to pay the current interest on the PDI bonds. However, on the basis of equal treatment to all creditors, a group of investors forced an acceleration of the Brady bond payments. The acceleration of the discount bonds triggered the cross-default provision in all of Ecuador's US\$6 billion Brady debt.
} 
Unfortunately we do not have enough bonds to use our implied default probabilities to trace out a term structure. But we can shed some light on this question by comparing the average implied default probabilities on pairs of instruments with different maturities issued by the same borrower. A number of comparisons are reported in Table 3. First consider the differences in the implied default probabilities on the discount and PDI bonds issued by Argentina and the discount and DC bonds issued by Venezuela. All of these are floating-rate bonds. Both discount bonds have longer maturity and the difference in maturity is reinforced by earlier amortization of Argentina's PDI bond and Venezuela's DC bond. In both cases, the longer maturity bond has a lower implied default probability but the difference is statistically significant at standard levels only for the first comparison. The comparison is rendered slightly less clean for Venezuelan discount and FLIR bonds and the Philippines' PCIR and new money bonds by different coupon rate features.

We can ask a similar question about bonds with different durations. Again, a positively sloped term structure of default risk would lead us to expect that shorter duration bonds would have lower implied default probabilities. The par bonds issued by Argentina, Brazil, Mexico and Venezuela share the same maturity date with the corresponding discount bonds. But floating rate bonds have shorter duration than fixed rate bonds. If the true model has a positively sloped term structure, we might expect to find the discount bonds to have lower implied default probabilities. And we do. The implied default probability on the discount (floating-rate) bond is statistically significantly lower in two out of four cases.

The evidence reported in Table 3 suggests that the constant conditional default probability model may be missing some feature of the pricing of bonds but does not point to a systematic term structure of credit risk (at least on average). Although some of the differences in the implied default probabilities across issues by a given borrower may be due to problems with the specification, it is difficult to see how these problems can explain all of the differences.

Another possible source of the differences in implied default probabilities may be

Table 3

Average differences in implied default probabilities ${ }^{\mathrm{a}}$

\begin{tabular}{llrr}
\hline Country & Bond pair & Average difference & $t$-Ratio \\
\hline \multirow{2}{*}{ Argentina } & Par-Discount & 0.617 & 3.501 \\
& Discount-PDI & -0.474 & -2.892 \\
Brazil & Par-Discount & 0.474 & 1.856 \\
Mexico & Par-Discount & 0.960 & 6.848 \\
Philippines & PCIR-New Money & 0.500 & 1.533 \\
Venezuela & Par-Discount & 0.276 & 1.347 \\
& Discount-DC & -0.363 & -1.298 \\
& Discount-FLIR & -1.104 & -2.585 \\
\hline
\end{tabular}

\footnotetext{
a Notes: the $t$-ratios for the average differences in the corresponding default probabilities are computed with an adjustment for autocorrelation up to four lags.
} 
differences in liquidity - more liquid bonds would have higher prices and lower implied default probabilities. As can be seen in Fig. 2, however, the differences in implied default probabilities appear to have a substantial transitory component. For example, the implied default probabilities of the Mexican par bond are sometimes above and sometimes below the implied default probabilities of the Mexican discount bond. Liquidity differences are unlikely to be a significant part of the story because those differences are likely to be quite persistent.

Might the differences in the implied default probabilities be due to anomalies in the relative valuation of bonds issued by the same borrower rather than specification errors in computing the implied probabilities? If the differences in the implied probabilities arise because of pricing anomalies, the substantial transitory component in the differences suggests that the pricing anomalies are subsequently corrected. That is, the Mexican par bond might be overpriced relative to the Mexican discount bond for a while, and then underpriced (again relative to the discount bond) for a while. If so, the differences in the implied default probabilities might be used to generate a profitable trading strategy. We now consider such a strategy.

\subsection{A simple trading strategy}

Consider two bonds (bond $i$ and bond $j$ ) issued by the same borrower. Since both bonds are issued by the same borrower, their true default probabilities are identical. Now suppose that bond $i$ is underpriced in the market at time $t-1$ relative to bond $j$. The undervalued bond will have a higher implied default probability so that $\rho_{i, t-1}>\rho_{j, t-1}$. If the market's undervaluation of the bond $i$ is a temporary pricing anomaly, an investor could exploit the anomaly by buying bond $i$ and selling bond $j$ short. Since the investor is buying one bond and selling another short, following this strategy does not expose the investor to the borrower's credit risk. The investor would then profit when the difference in relative valuation reverses (or at a minimum, upon maturity). If this trading strategy is successful, higher implied default probabilities will be associated with higher holding period returns in the future.

The hypothesis of no mispricing can be tested with the regression (3), where $h_{j, t}$ is the rate of return from holding the bond $j$, from $t-1$ to $t$.

$$
h_{i, t}-h_{j, t}=\alpha_{i, j}+\beta_{i, j}\left(\rho_{i, t-1}-\rho_{j, t-1}\right)+\epsilon_{t}
$$

The implied default probabilities at time $t-1$ are predetermined (they use only information available at $t-1$ ) so that ordinary least squares estimates are consistent. A statistically significant positive slope $\left(\beta_{i, j}\right)$ is evidence of a profitable trading strategy and therefore of transitory pricing errors in the market.

Table 4 reports the estimates of (3) for all possible pairs of bonds included in our sample. Of the 14 pairs, all have positive estimated slope coefficients, 12 of which are significant at the $10 \%$ level. And of these, 10 are significant at the $5 \%$ level. These results provide strong evidence that some of the differences in implied default probabilities for different issues by the same borrower are due to transitory difference 
Table 4

Predicting return differences with differences in implied default probabilities $^{\mathrm{a}}$

\begin{tabular}{|c|c|c|}
\hline Country/bond pair & Constant & Difference in default probability \\
\hline \multicolumn{3}{|l|}{ Argentina } \\
\hline \multirow[t]{2}{*}{ Discount-Par } & 0.110 & $10.879^{* * *}$ \\
\hline & $(0.085)$ & $(3.826)$ \\
\hline \multirow[t]{2}{*}{ Discount-PDI } & $0.214^{* * *}$ & $26.211^{* * *}$ \\
\hline & $(0.091)$ & $(8.207)$ \\
\hline \multirow[t]{2}{*}{ Par-PDI } & -0.055 & $11.147^{*}$ \\
\hline & $(0.087)$ & $(5.852)$ \\
\hline \multicolumn{3}{|l|}{ Brazil } \\
\hline \multirow[t]{2}{*}{ C-Discount } & 0.164 & 1.674 \\
\hline & $(0.121)$ & $(5.089)$ \\
\hline \multirow[t]{2}{*}{ C-Par } & 0.037 & -0.647 \\
\hline & $(0.126)$ & $(4.013)$ \\
\hline \multirow[t]{2}{*}{ Discount-Par } & 0.074 & $11.741^{* * *}$ \\
\hline & $(0.083)$ & $(3.103)$ \\
\hline \multicolumn{3}{|l|}{ Mexico } \\
\hline \multirow[t]{2}{*}{ Discount-Par } & 0.061 & $7.502^{* *}$ \\
\hline & $(0.104)$ & $(3.497)$ \\
\hline \multicolumn{3}{|l|}{ Philippines } \\
\hline \multirow[t]{2}{*}{ PCIR-NM } & -0.072 & $11.927^{* *}$ \\
\hline & $(0.095)$ & $(4.824)$ \\
\hline \multicolumn{3}{|l|}{ Venezuela } \\
\hline \multirow[t]{2}{*}{ DC-Discount } & -0.030 & $12.246^{* *}$ \\
\hline & $(0.076)$ & $(4.979)$ \\
\hline \multirow[t]{2}{*}{ DC-FLIR } & $0.144^{* * *}$ & $10.687^{* * *}$ \\
\hline & $(0.073)$ & $(3.074)$ \\
\hline \multirow[t]{2}{*}{ DC-Par } & -0.046 & $7.256^{*}$ \\
\hline & $(0.094)$ & $(3.872)$ \\
\hline \multirow[t]{2}{*}{ Discount-FLIR } & $0.139 *$ & $9.900^{* * *}$ \\
\hline & $(0.078)$ & $(3.145)$ \\
\hline \multirow[t]{2}{*}{ Discount-Par } & -0.018 & $13.340^{* * *}$ \\
\hline & $(0.075)$ & $(3.309)$ \\
\hline \multirow[t]{2}{*}{ FLIR-Par } & -0.106 & $5.922^{* * *}$ \\
\hline & $(0.092)$ & $(2.232)$ \\
\hline
\end{tabular}

a Note: the difference in the rates of return at time $t$ is regressed on the difference of the implied default probabilities at time $t-1$. Standard errors, adjusted for potential heteroscedasticity and autocorrelation are given in parentheses. One, two, and three asterisks indicate significance at the 10, 5 and $1 \%$ levels, respectively.

in the relative pricing of the issues. ${ }^{19}$ The profitability of this trading strategy indicates that the market corrects relative pricing anomalies in the short to medium run, but not instantly.

The profits an investor could earn by exploiting the information contained in the

\footnotetext{
${ }^{19}$ Lee et al. (1996) conclude that secondary market for developing country loans has become more efficient over time. We find that there is still some evidence of pricing errors, at least in the Brady bond
} 
differences in the implied default probabilities are economically meaningful as well as statistically significant. Table 5 includes two measures of the returns to exploiting potential pricing anomalies reflected in differences in the implied default probabilities. The first measure takes as the starting point an investor who holds an equally-weighted portfolio of all Brady bonds issued by a given borrower. We compute the increase in the rate of return that investor would earn by buying a given borrower's Brady bond with the highest implied default probability each period rather than holding the equally weighted portfolio. This added return, expressed as an annual percentage rate is what we label the return to Strategy 1 in Table $5 .^{20}$ The added return is positive for all countries and range from $<200$ basis points for Mexico to $>700$ basis points for Venezuela. ${ }^{21}$

Table 5

Returns to two trading strategies ${ }^{\mathrm{a}}$

\begin{tabular}{llc}
\hline Country & Return on strategy 1 & Profit from strategy 2 \\
\hline Argentina & 3.01 & 9.32 \\
Brazil & 3.52 & 0.34 \\
Mexico & 1.97 & 3.94 \\
Philippines & 3.91 & 7.82 \\
Venezuela & 7.07 & 15.82 \\
\hline
\end{tabular}

a Note: the return on Strategy 1 is the increase in the rate of return earned from a dynamic strategy of buying the Brady bond (of a given issuer) with the highest implied default probability above that earned on an equally weighted portfolio of all Brady bonds of that issuer, expressed as an annual percentage rate (uncompounded). The profit on Strategy 2 is the profit from a zero-investment strategy of buying the Brady bond with the highest implied default probability and shorting the bond with the lowest implied default probability, also expressed as an annual percentage rate. Thus it is the profit (in dollars) for each US\$100 worth of short sales and purchases.

market. Our evidence comes from the trading rules that exploits potential errors in the relative pricing of multiple issues of several borrowers. Since Lee et al. examine the secondary market for loans, their data includes only one price per borrower.

${ }^{20}$ When the prices of all bonds decline, such as during the Tequila crisis, any holding of Brady bonds will yield negative rates of return. For instance, the value of an equally-weighted portfolio of the Mexican discount and par bonds experienced $33.55 \%$ drop in the first 3 months following the Mexican crisis. However, when all prices are going down, this trading strategy may mitigate losses. If one were to have bought the bond suggested by the trading strategy instead of an equally-weighted portfolio immediately before the crisis, the 3 month holding period return would be higher by 348 basis points for Mexico, by 607 basis points for Argentina, by 748 basis points for Brazil, and by 112 basis points for the Philippines. Only for Venezuela would the value of the advice have been negative (150 basis points).

${ }^{21}$ Transactions costs will eat into some of these profits. The bid-ask spread on relatively liquid Brady bonds, such as the Argentina, Brazilian, Mexican and Venezuelan Brady bonds, is typically around US $\$ 0.25$, although large or frequent traders can often get better terms. This investment strategy required an average of 3.18 trades per year for Argentina, 2.29 for Brazil, 2.59 for Mexico and 6.76 for Venezuela. Thus on these more liquid bonds the annualized profits (after transactions costs) for a typical trader following this strategy would have been 187 basis points for Argentina, 260 basis points for Brazil, 108 basis points for Mexico and 451 basis points for Venezuela. For less liquid Brady bonds the bid-ask spread is often as high as US $\$ 0.75$ or even a dollar. At a US\$1 bid-ask spread, the 3.38 average transactions per 
The second measure is the payoff to a zero investment strategy similar to the trading rule behind the regression results. An investor following this strategy buys a given borrower's Brady bond with the highest implied default probability each period and shorts that borrower's Brady bond with the lowest implied default probability. The investor earns the difference in the holding period returns, which we report in Table 5 and label the profit from Strategy 2. The strategy yields positive profits with payoffs for each US\$100 worth of buying and shorting, ranging from 34 cents annually for the Brazilian bonds to more than US\$15 annually for the Venezuelan bonds.

A number of firms carrying out leveraged relative value trading strategies experienced significant losses following the Russian default. In order to determine whether the profitable trading strategy that we have identified persisted after the disruptions in 1998, we test for structural stability of the regression coefficients in (3). In general, the evidence suggests that there has not been a break in the relationship. Of the 14 pairs, only one (the Venezuelan DC and FLIR bonds) shows evidence of a break at the 5\% level around the time of the Russian default. There is evidence of a break at the $10 \%$ level for one additional pair (the Venezuelan DC and par bonds). We found no evidence of a structural break — at either the $5 \%$ or $10 \%$ level - around the time of the Mexican crisis. This evidence, combined with the evidence in footnote 20 suggests that the gains from actively buying the bond with the highest implied default probability have persisted over time.

\section{Conclusion}

In this paper we present estimates of a summary measure of credit quality for a sample of Brady bonds issued by five countries and examine the relative pricing of these bonds. Our measure of credit quality is the default probability implied by observed market prices under the assumption that, at each point in time, the probability of default (conditional on no prior default having occurred) at all future dates is constant. These values provide a potentially useful indicator that takes into account all of the features of each individual bonds. This measure of credit quality can therefore be compared across bonds, across borrowers, and over time. And it should change over time only in response to changes in perceived credit risk. Hence it may be a useful substitute, for example, for the market price, the yield to maturity, or the credit spread of the bond.

We also examine the pricing behavior in the Brady bond market. The probability of default should be identical for all bonds issued by a given borrower. But we find differences in these implied probabilities across bonds issued by the same borrower. If these differences reflect pricing errors, undervalued bonds should have high implied default probabilities and overvalued bonds should have low default prob-

year on the less liquid Philippines bonds would have resulted in a loss of 26 basis points from following this strategy. 
abilities. We find that trading strategies using differences in the implied default probabilities to identify overvalued and undervalued bonds are indeed profitable. The success of these trading strategies might therefore reflect transitory errors in the relative pricing of different issues by the same borrower.

\section{Acknowledgements}

The authors gratefully acknowledge the helpful comments of two referees and the suggestions and assistance of Susan Collins, Chul Park, Ivan Pastine, and Srikan Seshadri. This paper has been presented at the Royal Economic Society's 1999 Annual Conference. The authors would like to thank the conference participants for helpful comments. Responsibility for errors remains their own.

\section{References}

Berg, A., Sachs, J., 1988. The debt crisis: structural explanations of country performance. Journal of Development Economics 29 (3), 271-306.

Bierman, H., Haas, J., 1975. An analytical model of bond risk yield differentials. Journal of Financial and Quantitative Analysis 10 (5), 757-773.

Boehmer, E., Megginson, W., 1990. Determinants of secondary market prices for developing country syndicated loans. Journal of Finance 45 (5), 1517-1540.

Claessens, S., Pennachhi, G., 1996. Estimating the likelihood of Mexican default from the market prices of Brady bonds. Journal of Financial and Quantitative Analysis 31 (1), 109-126.

Das, S., Tufano, P., 1995. Pricing credit-sensitive debt when interest rates, credit ratings, and credit spreads are stochastic. Harvard Business School working paper.

Edwards, S., 1986. The pricing of bonds and bank loans in international markets. European Economic Review 30 (3), 565-589.

Fernandez, R., Ozler S., 1991. Debt concentration and secondary market prices: a theoretical and empirical analysis. National Bureau of Economic Research working paper No. 3654.

Hajivassiliou, V., 1989. Do the secondary markets believe in life after debt? In: Huain, I., Diwan, I. (Eds.), Dealing with the Debt Crisis. World Bank, Washington, DC, pp. 276-291.

Jarrow, R., Lando, D., Turnbull, S., 1994. A Markov model for the term structure of credit risk spreads. Cornell University working paper.

Kim, I.J., Ramaswamy, K., Sundaresan, S., 1993. Does default risk in coupons affect the valuation of corporate bonds? A contingent claims model. Financial Management 22 (3), 117-131.

Lee, S.H., Sung, H.M., Urrutia, J.L., 1996. The behavior of secondary market prices of LDC syndicated loans. Journal of Banking and Finance 20 (3), 537-554.

Leland, H.E., Toft, K.B., 1996. Optimal capital structure, endogenous bankruptcy, and the term structure of credit spreads. Journal of Finance 51 (3), 987-1019.

Longstaff, F.A., Schwartz, E.S., 1995. A simple approach to valuing risky fixed and floating rate debt. Journal of Finance 50 (3), 789-820.

Merton, R.C., 1974. On the pricing of corporate debt: the risk structure of interest rates. Journal of Finance 29 (2), 449-470.

Ozler, S., Huizinga, H., 1992. Bank exposure, capital and secondary market discounts on developing country debt. National Bureau of Economic Research working paper No. 3961.

Purcell, A., Orlanski, D., 1988. Developing country loans: a new valuation model for secondary market trading. Salomon Brothers, corporate bond research.

Sachs, J., Huizinga, H., 1987. US commercial banks and the developing country debt crisis. Brookings Papers on Economic Activity 1987 (2), 555-601. 
Stone, M., 1991. Are sovereign debt secondary market returns sensitive to macroeconomic fundamentals? Evidence from the contemporary and interwar markets. Journal of International Money and Finance 10 (S3), S100-S122.

Wu, C., Yu, C.H., 1996. Risk aversion and the yield of corporate debt. Journal of Banking and Finance $20(2), 267-281$.

Yawitz, J.B., 1977. An analytical model of interest rate differentials and different default recoveries. Journal of Financial and Quantitative Analysis 12 (3), 481-490.

Yawitz, J.B., Maloney, K.J., Ederington, L.H., 1985. Taxes, default risk, and yield spreads. Journal of Finance 40 (4), 1127-1140. 